\title{
CORRESPONDENCE
}

\section{Chronic Critical Limb Ischemia}

by Dr. med. Arndt Dohmen, Dr. med. Stephan Eder, Dr. med. Wulf Euringer, Prof. Dr. med. Thomas Zeller, Prof. Dr. med. Dr. h. c. Friedhelm Beyersdorf in volume $6 / 2012$
Dr. med. Ulrich Kamphausen

Gemeinschaftspraxis für Gefäßmedizin

Gefäßzentrum Mönchengladbach DGG

ukamphausen@gpg-mg.de

Conflict of interest statement

The author has received honoraria for speaking from Leo Pharma.

\section{Continuous Control}

The authors rightly point out that among basic diagnostic investigations, Doppler sonography is of great importance, but that this method is known to fail in diabetic media sclerosis. In the postoperative care of a patient after a bypass procedure, Doppler blood pressure measurement can therefore not be used for reliable follow-up checks. The indication for "compression therapy" can therefore not be determined by using Doppler pressure readings either.

"Compression therapy" in the traditional sense should be considered problematic in perfusion disorders as a matter of principle and should not be carried out. There is, however, evidence supporting the use of non-pulling padded compression bandaging of the affected leg by means of short stretch bandages. Padded in this context refers to systematic interdigital cotton padding and wrapping the entire lower leg, and possibly also the thigh, in this padding. The region of the heel as well as the tibial shin need to be protected from local pressure damage by using double padding layers.

Because ischemia always produces edema, which leads to further deterioration of local nutrition, compression therapy in the described manner is of enormous importance during aftercare. It also complements manual lymphatic drainage. These procedures can be used easily and effectively in reperfusion edema. They slow down the development of postoperative wound healing problems (even though this has not been verified scientifically), especially in the distal lower leg. This is also the case for local patch removal from the lower leg. Obviously, it is essential that patients having such treatment are followed up several times every day - they will be primarily inpatients. For this reason, we regard the often seen "whole-foot padded boots" as an abomination. We increasingly use compression stockings in patients-who will subsequently be outpatients - whose compression power in the ankle region is no higher than about $15 \mathrm{~mm}$ pressure. Those patients also need continuous monitoring for as long as compression is used.

DOI: 10.3238/arztebl.2012.0542a

\section{REFERENCES}

1. Dohmen A, Eder S, Euringer W, Zeller T, Beyersdorf F: Chronic critical limb ischemia. Dtsch Arztebl Int 2012; 109(6): 95-101.

\section{Neither Procedure Is Superior}

The authors emphasized that thus far no scientific reason exists for preferring open surgery or endovascular infrapopliteal vascular interventions (1). According to the consensus of the International Working Group on the Diabetic Foot (2), neither procedure is superior to the other, since no randomized prospective comparative studies exist. The results seem comparable for both procedures and seem to depend on the distribution pattern of the peripheral arterial occlusive disease and the expertise at the vascular center. Vascular surgical patients with critical ischemia seem to have more complex occlusive patterns, and the treatment conditions become more difficult by prior endovascular treatments.

In contrast to the authors we think that long term results for patency and amputation in patients with chronic critical limb ischemia are important, because one in every two patients will still be alive after five years. This calls for sustained revascularization and long-term follow-up examinations.

The diagnostic algorithm in critical limb ischemia published by the authors prefers digital subtraction angiography (DSA) of the pelvic and leg arteries to color coded duplex sonography and magnetic resonance angiography (MRA). This is outdated information and contradicts current scientific guidelines (3).

In cases where intervention and bypass surgery are not possible the authors recommend connective tissue massage to widen peripheral vessels. This will result in the redistribution of blood in the form of a "steal phenomenon" distal to the occlusions and can cause more harm than good. No scientific evidence exists for spinal cord stimulation for pain treatment.

Diabetic patients with chronic critical limb ischemia who have concomitant polyneuropathy may develop necrosis without pain. The Fontaine classification for peripheral arterial occlusive disease hence does not apply to these patients. Chronic critical limb ischemia should be looked out for early on (4). It may be that vascular therapy ("leg catheter") makes sense even in asymptomatic neuro-ischemic diabetes patients. To date, the guidelines do not include any relevant information owing to a lack of evidence.

DOI: 10.3238/arztebl.2012.0542b 


\section{REFERENCES}

1. Dohmen A, Eder S, Euringer W, Zeller T, Beyersdorf F: Chronic critical limb ischemia. Dtsch Arztebl Int 2012; 109(6): 95-101.

2. Schaper NC, Andros G, Apelqvist J, et al.: Specific guidelines for the diagnosis and treatment of peripheral arterial disease in a patient with diabetes and ulceration of the foot 2011. Diabetes Metab Res Rev 2012; 28(Suppl 1): 236-7

3. Bauer H, Germann G, Gries FA, et al.: Nationale Versorgungsleitlinie Typ-2-Diabetes. Präventions- und Behandlungsstrategien für Fußkomplikationen. Kirchheim, Mainz 2009. (www.diabetes.versor gungsleitlinien.de)

4. Taylor SM, Cull DL, Kalbaugh CA, et al.: Comparison of interventional outcomes according to preoperative indication: a single center analysis of 2240 limb revascularizations. J Am Coll Surg 2009; 208: $770-8$

Prof. Dr. med. Gerhard Rümenapf

Klinik für Gefäßchirurgie, Diakonissen-Stiftungs-Krankenhaus Speyer

Gerhard.Ruemenapf@diakonissen.de

Prof. Dr. med. Ernst Chantelau, Bremen

Dr. med. Stephan Morbach, Marienkrankenhaus Soest

Conflict of interest statement

Professor Rümenapf has received conference and hotel expenses from Jotec. Dr Morbach has received honoraria for acting as consultant from NovoNordisk Olympus, and Biotech as well as moneys into third-party accounts from Olympus and Biotech. Professor Chantelau declares that that no conflict of interest exists.

\section{Highly Effective}

Spinal cord stimulation (SCS) was mentioned only in passing in what was otherwise an excellent review article. SCS is a minimally invasive procedure whose effectiveness has been evaluated in a multitude of studies (2), the AWMF (Arbeitsgemeinschaft der Wissenschaftlichen Medizinischen Fachgesellschaften, the Working Group of the Scientific Medical Specialty Societies) has made a strong recommendation in this context (3). According to our own experiences this method has a sustained effect on pain and increases patients' walking capacity. The effect on the amputation rate is currently the subject of an observational study. The technique should be employed without delay in cases where surgical or endovascular revascularization procedures in stages IIb, III, and IVa according to Fontaine have been exhausted.

DOI: 10.3238/arztebl.2012.0543a

\section{REFERENCES}

1. Dohmen A, Eder S, Euringer W, Zeller T, Beyersdorf F: Chronic critical limb ischemia. Dtsch Arztebl Int 2012; 109(6): 95-101.

2. Ubbink DT, Vermeulen H: Spinal cord stimulation for non-reconstructable chronic critical leg ischaemia. Cochrane Database Syst Rev 2005; 3: CD004001.

3. Tronnier V, Baron R, Birklein F, Eckert S, Harke H, Horstkotte D, Hügler P. Hüppe M, Kniesel B, Maier C, Schütze G, Thoma R, Treede RD, Vadokas V; Arbeitsgruppe zur Erstellung der S3-Leitlinie: Epidurale Rückenmarkstimulation zur Therapie chronischer Schmerzen. Zusammenfassung der S3-Leitlinie. Schmerz 2011; 25: 484-92.

Dr. med. Donatus Cyron

Klinik für Neurochirurgie, Städtisches Klinikum Karlsruhe

Donatus.Cyron@klinikum-karlsruhe.de
Prof. Dr. med. Martin Storck

Klinik für Gefäß- und Thoraxchirurgie, Städtisches Klinikum Karlsruhe

\section{Conflict of interest statement}

The authors declare that that no conflict of interest exists.

\section{In Reply:}

Kamphausen added an interesting aspect to our comments on compression treatment. The combination of a compression bandage and protection from local pressure injuries by using cotton wool padding into the interdigital region makes perfect sense conceptually. Owing to our own lack of experience with this bandaging technique, however, we cannot assess the therapeutic effect. In principle, the use of compression therapy is justified on the basis of the Doppler pressure readings, because especially in patients with diabetic media sclerosis, arterial perfusion is not relevantly impaired by the compression related pressure values of, at most, $40-50 \mathrm{~mm}$ $\mathrm{Hg}$.

Rümenapf, Chantelau, and Morbach agreed that the results of open surgical and interventional infrapopliteal revascularization have shown comparable results, according to the evidence. The comment that vascular surgical procedures are made more difficult by prior endovascular treatment underlines our recommendation to ensure in all peripheral vascular interventions that a distal segment of uninjured artery is left that can be used for a functioning bypass anastomosis.

Even though the long-term patency of vascular revascularizations is promising in terms of the prognosis, the primary objective of treatment is to save the limb, and this is often possible after successful healing of the original tissue lesion even in spite of repeat occlusion of the treated vascular segments.

We believe that the S3 guideline for peripheral arterial occlusive disease does not adequately evaluate digital subtraction angiography (DSA) for the subject we focused on-precise delineation of all crural and pedal arteries under the conditions of the critical limb ischemia, since in comparing the methods no differentiation is made with regard to clinical stages nor different regions of disease. Magnetic resonance angiography (MRA) has its greatest weaknesses in these clinical conditions. The combination of Duplex sonography or the pelvic arteries and DSA of the infrainguinal vessels that we described saves substantial amounts of contrast medium and therefore acknowledges the particular risks of the method especially in diabetes patients. The current guidelines do not specially evaluate the use of DSA when targeting exclusively the problem area. Furthermore, the algorithm of the national disease management guideline for diabetes that we cited as a reference also recommends primarily DSA before revascularization procedures in the lower leg region (2).

Steal effects are possible in any vasodilating procedures - for this reason, such measures always requite continuous clinical monitoring. 
In view of the risk of possible repeated occlusions with possible clinical deterioration, we remain unconvinced by the suggestion to quasi-prophylactically revascularize arteries in the lower leg in diabetes patients with polyneuropathy in order to prevent critical limb ischemia. Structured training, however, has been proved to be effective for a prophylaxis of foot lesions (3).

With regard to the question of scientific evidence for SCS we agree with Cyron and Storck, who rightly point out the multitude of studies that have evaluated this method and achieved good results - findings that have started to find their way into guideline recommendations.

$$
\text { DOI: 10.3238/arztebl.2012.0543b }
$$

\section{REFERENCES}

1. Diagnostik und Therapie der peripheren arteriellen Verschlusskrankheit (PAVK). AWMF-Leitlinien-Register 065-003, 2009: S. 27 und S. 31.

2. Bauer H, Germann G, Gries FA, et al.: Nationale Versorgungsleitlinie Typ-2-Diabetes. Präventions- und Behandlungsstrategien für Fußkomplikationen, Version 2.8, 02/2010, S. 28.
3. McCabe, Stevenson RCF, Dolan AM: Evaluation of a diabetic foot screening and protection programme. Diabet Med 1998; 15: 80-4.

4. Tronnier V, Baron R, Birklein F, Eckert S, Harke H, Horstkotte D, Hügler P, Hüppe M, Kniesel B, Maier C, Schütze G, Thoma R,

Treede RD, Vadokas V; Arbeitsgruppe zur Erstellung der S3-Leitlinie: Epidurale Rückenmarkstimulation zur Therapie chronischer Schmerzen. Zusammenfassung der S3-Leitlinie. Schmerz 2011; 25: 484-92.

5. Dohmen A, Eder S, Euringer W, Zeller T, Beyersdorf F: Chronic critical limb ischemia. Dtsch Arztebl Int 2012; 109(6): 95-101.

\section{Dr. med. Arndt Dohmen}

Interdisziplinäres Gefäßzentrum

Universitätsklinikum Freiburg

arndt.dohmen@uniklinik-freiburg.de

Conflict of interest statement

Professor Zeller acts as consultant to Cordis, Cook, ev3, and Medtronic. He has received lecture fees and reimbursement of training and accommodation costs from ev3, Cordis, Medtronic, Cook, Gore, Biotronik, Abbott, Vascular IDEV, and Straub Medical.

Dr Eder has received reimbursement of costs for congress attendance and accommodation from Gore and Bard.

Dr Euringer has received reimbursement of costs for congress attendance and accommodation from Terumo, Nicolei, and Vaskutek. 